\title{
Comparative Performance Analysis of AODV, DSR, DSDV, LAR1 and WRP Routing Protocols in MANET using GloMoSim 2.0.3 Simulator
}

\author{
Vishal Gupta \\ Assistant Professor \\ Bipin Tripathi Kumaon Institute of Technology \\ Dwarahat - 263653, Almora, Uttarakhand, INDIA
}

\begin{abstract}
A Mobile Ad-hoc Network (MANET) is a collection of wireless mobile nodes that communicates with each other without using any existing infrastructure or centralized supervision. A major design issue for an efficient and effective routing protocol for real MANETs is, therefore, to achieve optimum values of performance parameters under network scenarios where nodes are subjected to different types of mobility that dynamically change the network topology. In this paper, I am comparing the performance of five prominent Mobile Ad-hoc Network (MANET) protocols. My simulative study on MANET routing protocols and mobility models aims to determine the performance of current MANET routing protocols with respect to various mobility models implemented in GloMoSim 2.0.3 simulator. I compare a number of routing protocols including AODV, DSDV, DSR, LAR1 and WRP and the performance analysis is based on different network metrics such as Average End to End delay, Throughput, Collisions and Energy Consumption for both stationary and mobile nodes. The results of my extensive network simulations are tabulated along with a comprehensive analysis. The effort allows a fair comparison of the capabilities and limitations of different types of mobility patterns and their suitability for contemporary MANET routing protocols.
\end{abstract}

\section{General Terms}

Protocols, MANET, DSDV, AODV, DSR, LAR1, WRP, GloMoSim 2.0.3.

\section{INTRODUCTION}

A mobile Ad-hoc network (MANET) is an autonomous, infrastructure-less, self-configuring and self-healing system of mobile nodes connected by wireless links. The nodes are free to move about randomly and may join or leave the network at their will [1]. Due to this element of randomness, the network topology becomes unpredictable and may change rapidly. The important considerations in the performance of MANETs are the nature of the participating nodes, and the mobility of the mobile nodes. MANETs are composed of power limited devices with a limited transmission range, so in most cases they will not be able to communicate directly with the destination device. Thus, communication must be relayed through intermediate devices resulting in multiple-hops to the destination. MANETs may also be composed of different types of devices, which have different transmission ranges, this heterogeneous situation results in various problems, for example, unidirectional links. Unidirectional links cause problems during the search for a path from the source to destination. Due to differing transmission ranges of intermediate nodes, a path from the source to the destination might not be valid from the destination to the source since one node might not be able to transmit to its preceding node in the route [2]. The motion of nodes in MANETs results in nodes frequently going out of the transmission range of other nodes, thus interfering with MANET routing. Also, since the MANET is a decentralized network, information about the state of the network is not recognized to any one node. Thus to support the routing function, nodes frequently exchange information to become "conscious" of the state of the network.

In spite of the problems of MANETs, MANETs have a tremendous potential to be used in various real-world situations such as battle field scenarios, rescue operations and vehicular networks, where setting up a traditional network infrastructure would be implausible [3]. There are lots of protocols designed for MANET envornment such as FSR, AODV, LAR1, ZRP,WRP, OLSR, DSR, DSDV, STAR, etc. The focus of this paper is on camparative analysis of AODV, DSDV, DSR, LAR1 and WRP for different node densities in which nodes may be mobile or stationary.

\section{ROUTING ALGORITHMS}

\subsection{AODV}

Ad-Hoc On-Demand Distance Vector Routing (AODV) is one of the revolutionary routing algorithms for MANETs and has become very popular in literature with many newer algorithms comparing their efficacy with respect to AODV. AODV is a purely reactive routing algorithm and establishes a route to the destination only on demand. AODV also avoids the countingto-infinity problem of other distance-vector protocols by using sequence numbers on route updates. Each MANET routing algorithm consists of three major mechanisms: Route discovery, Route maintenance, and Route error correction [4].

The benefit of AODV is in its reactive nature that it experiences no network overhead due to transmission of control packets on links that are not being used. AODV is also a very simple algorithm, and does is not high time or memory complexity [5]. However AODV requires more time to establish a connection, and the initial communication to establish a route is heavier than some other approaches.

\subsection{DSR}

The Dynamic Source Routing (DSR) protocol is a distancevector routing protocol for MANETs. When a node generates a packet to a certain destination and it does not have a known route to that destination, this node starts a route discovery 
procedure. Therefore, DSR is a reactive protocol. One benefit of DSR is that no periodic routing packets are required. DSR also has the capability to handle unidirectional links [6]. Since DSR dis- covers routes on-demand, it may have poor performance in terms of control overhead in networks with high mobility and heavy traffic loads. Scalability is said to be another disadvantage of DSR, because DSR relies on blind broadcasts to discover routes.

To handle unreliable transmissions of control messages, DSR either relies on the underlying MAC protocol to provide guaranteed delivery or it retransmits control messages for a certain number of times. Since DSR is a reactive protocol, it cannot tell whether a destination is unreachable or the route request is lost. Therefore, it suffers more over- head if the underlying MAC layer does not support guaranteed delivery [7]. This is a common problem for reactive routing protocols because when no reply message is heard, routers with a reactive routing protocol cannot tell the difference between the case of a transmission error and the case of unreachable nodes. Reactive routing protocols try to use extra acknowledgements or a small number of retransmissions to solve this problem and, thus, introduce more overhead. Proactive routing protocols periodically broadcast control messages and remove local routing entries if they time out. Hence, they do not have this problem. But, of course, the periodically broadcast control messages con- tribute to overhead [8].

\subsection{DSDV}

Destination-Sequenced Distance-Vector Routing (DSDV) is a table-driven routing scheme for ad hoc mobile networks based on the Bellman-Ford algorithm. It was developed by C. Perkins and P. Bhagwat in 1994. The main use of the algorithm is to solve the routing loop problem [9]. Each entry in the routing table contains a sequence number, the sequence numbers which are generally even if a link is present otherwise an odd number is used. The number is generated by the destination, and the sender needs to send out the next update with this number [10]. Routing information is dispersed between nodes by sending full dumps occasionally and smaller incremental updates more frequently [11].

\subsection{LAR1}

Location-Aided Routing (LAR) is an on-demand routing protocol which exploits location information of a mobile node. It is similar to DSR, but with the additional requirement of GPS information [12]. Location aided routing is an enhancement to flooding algorithms to reduce flooding overhead in the network. Most on-demand protocols, including DSR and AODV use flooding to obtain a route to the destination. LAR aims to reduce the overhead to send the route requests only into a specific area, which is likely to contain the destination [13].

For this purpose the notions of expected zone and request zone are introduced. The expected zone covers the area in which the destination is expected. Since the expected zone need not contain the source node, a larger area must be covered by flooding [14]. This expanded expected zone is called request zone and is used to restrict the flooding; i.e. only nodes that are part of the request zone can forward a route request. On unsuccessful route discoveries, the request zone may need to be expanded further, possibly covering the whole network [15]. Such subsequent route requests increase the initial latency for connections. This results in a tradeoff between reduced overhead and increased latency which needs to be balanced carefully.
In scheme 1 (implemented), the source defines a circular area in which the destination may be located, determined by the following information [16]:

- The destination location known to the source

- The time instant when the destination was located at that position

- The average moving speed of the destination.

The smallest rectangular area that includes this circle and the source is the request zone. This information is attached to a ROUTE REQUEST by the source and only nodes inside the request zone propagate the packet [17]. If no ROUTE REPLY is received within the timeout period, the source retransmits a ROUTE REQUEST via pure flooding [18].

\subsection{WRP}

The Wireless Routing Protocol (WRP) is a proactive unicast routing protocol for mobile ad-hoc networks (MANETs). WRP uses an enhanced version of the distance-vector routing protocol, which uses the Bellman-Ford algorithm to calculate paths [19]. Because of the mobile nature of the nodes within the MANET, the protocol introduces mechanisms which reduce route loops and ensure reliable message exchange [11]. WRP, similar to DSDV, inherits the properties of the distributed Bellman-Ford algorithm. To counter the count-toinfinity problem and to enable faster convergence, it employs a unique method of maintaining information regarding the shortest distance to every destination node in the network and the penultimate hop node on the path to every destination node [20]. Since WRP, like DSDV, maintains an up-to-date view of the network, every node has a readily available route to every destination node in the network. It differs from DSDV in table maintenance and in the update procedures [12]. While DSDV maintains only one topology table, WRP uses a set of tables to maintain more accurate information [21]. The tables that are maintained by a node are the following: distance table (DT), routing table (RT), link cost table (LCT), and a message retransmission list (MRL).

\section{SIMULATION MODEL AND MODELS}

In this work, GloMoSim 2.0.3 network simulator has been used to evaluate the performance of AODV, DSR, DVRP, WRP and LAR1 routing protocols of mobile ad-hoc networks. The physical medium used is 802.11 PHY with a data rate of 2 Mbps. The MAC protocol used is the 802.11 MAC protocol, configured for MANET mode. In this work wireless module of IEEE $802.11 \mathrm{~b}$ is used to enable mobility of the wireless nodes. IEEE $802.11 \mathrm{~b}$ support more accurate wireless models for propagation, path loss, multipath fading and reception on wireless networks. The simulations are carried out for network densities of 25,50 and 75 nodes respectively. The area considered for the above network densities are $500 \mathrm{~m}$ X 500m (25, 50 and 75 nodes) for stationary nodes and nodes with mobility of $10 \mathrm{mps}$. Simulations are configured for the performance evaluation of different routing protocols with the metrics like throughput, end to end delay, collisions and energy consumption at the destination for stationary and nodes with mobility of $10 \mathrm{mps}$ respectively as given in table 1 . 
Table 1: Scenario Parameters

\begin{tabular}{|c|c|c|}
\hline Routing protocols & \multicolumn{2}{|c|}{ AODV,DSR, LAR1,DVRP \& WRP } \\
\hline Radio type & \multicolumn{2}{|c|}{$802.11 \mathrm{~b}$} \\
\hline No. of channels & \multicolumn{2}{|l|}{ One } \\
\hline Channel frequency & \multicolumn{2}{|c|}{$2.4 \mathrm{GHz}$} \\
\hline Mobility & None & Random Way Point \\
\hline Mobility speeds & None & 0 to $10 \mathrm{mps}$ \\
\hline Path loss model & \multicolumn{2}{|c|}{ Two Ray } \\
\hline Pause time & \multicolumn{2}{|c|}{30 second } \\
\hline Simulation time & \multicolumn{2}{|c|}{300 second } \\
\hline Battery model & \multicolumn{2}{|c|}{ Linear model } \\
\hline Simulation area & \multicolumn{2}{|c|}{$500 \mathrm{~m} \times 500 \mathrm{~m}$} \\
\hline Number of nodes & \multicolumn{2}{|c|}{$25,50,75$} \\
\hline Simulator & \multicolumn{2}{|c|}{ GloMoSim 2.0.3 } \\
\hline
\end{tabular}

\section{RESULTS}

The various performance metrics of these routing protocols are studied for stationary and mobile nodes with different node densities and the results are shown below accordingly.

\subsection{Average End to End Delay}

Figures 1 and 2 shows the variation in average end to end delay of various routing protocols considered for mobile and stationary nodes with respect to node densities 25,50 and 75 nodes respectively. Table 2 and 3 shows values of throughput for different node densities for mobile and stationary nodes respectively. I find that average end to end delay for DSR protocol is maximum and AODV protocol is minimum for 25 and WRP protocol for 50 and 75 mobile node scenarios (Figure 1) and average end to end delay for LAR1 protocol is maximum and DSR protocol is minimum for 25,50 and 75 stationary node scenarios (Figure 2).

Table 2: Average End to End Delay for 25, 50 and 75 mobile nodes

\begin{tabular}{|c|c|c|c|c|c|}
\hline $\begin{array}{c}\text { Node } \\
\text { with } \\
\text { mobility } \\
(10 \mathrm{mps})\end{array}$ & AODV & DSDV & DSR & LAR1 & WRP \\
\hline 25 & 0.0164 & .02234 & 23.5593 & 0.2228 & 0.0246 \\
\hline 50 & 0.4582 & 0.1216 & 21.6214 & 0.4998 & 0.1148 \\
\hline 75 & 0.0478 & 0.1469 & 0.5738 & 0.4419 & 0.2772 \\
\hline
\end{tabular}

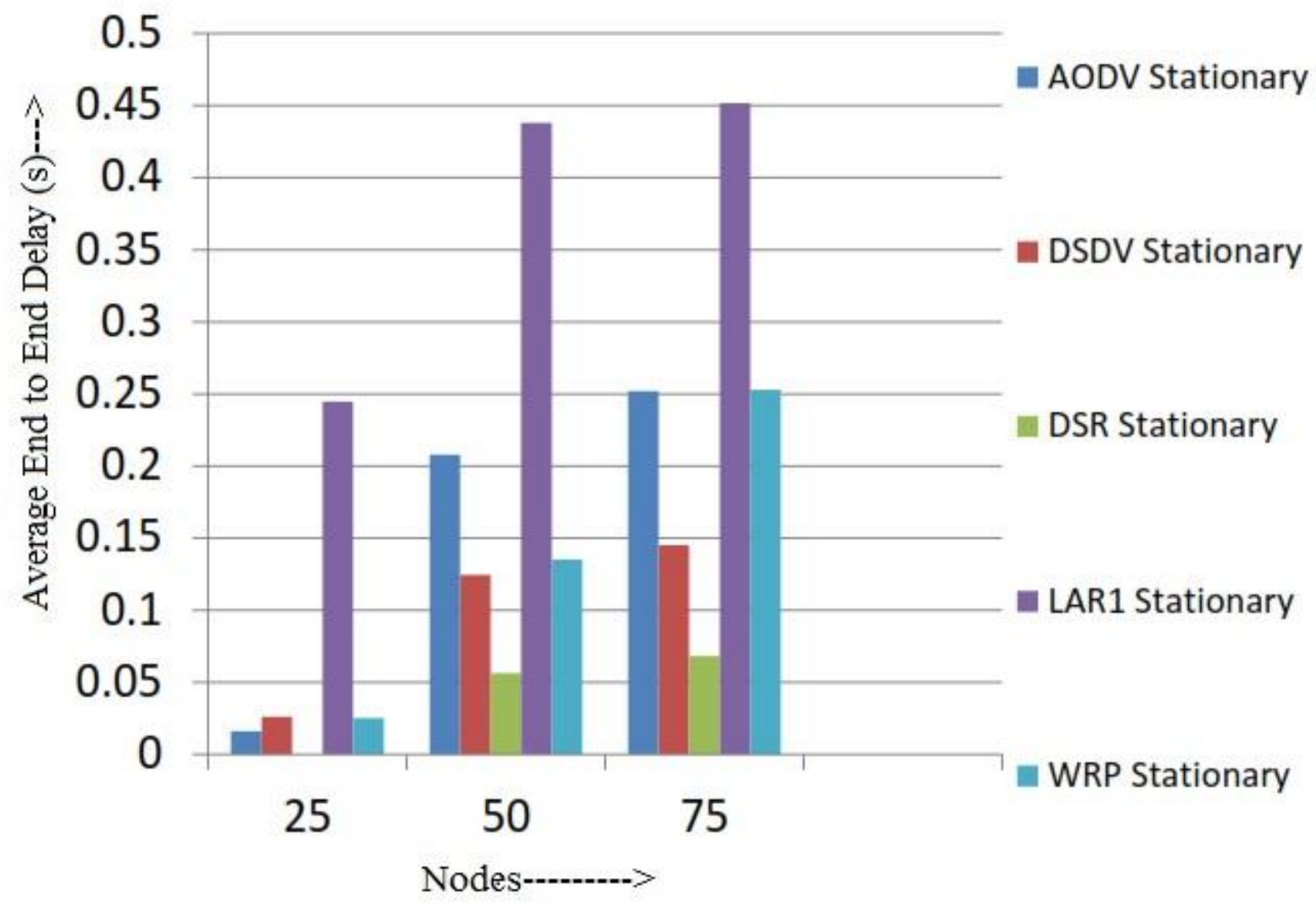

Fig 1: Average End to End Delay for 25, 50 and 75 mobile nodes 
Table 3: Average End to End Delay for 25, 50 and 75 Stationary nodes

\begin{tabular}{|c|c|c|c|c|c|}
\hline $\begin{array}{c}\text { Statio- } \\
\text { nary } \\
\text { node }\end{array}$ & AODV & DSDV & DSR & LAR1 & WRP \\
\hline 25 & 0.0162 & 0.0262 & 0.0000 & 0.2446 & 0.0252 \\
\hline 50 & 0.2078 & 0.1246 & 0.0563 & 0.4380 & 0.1353 \\
\hline 75 & 0.2520 & 0.1453 & 0.0683 & 0.4516 & 0.2528 \\
\hline
\end{tabular}

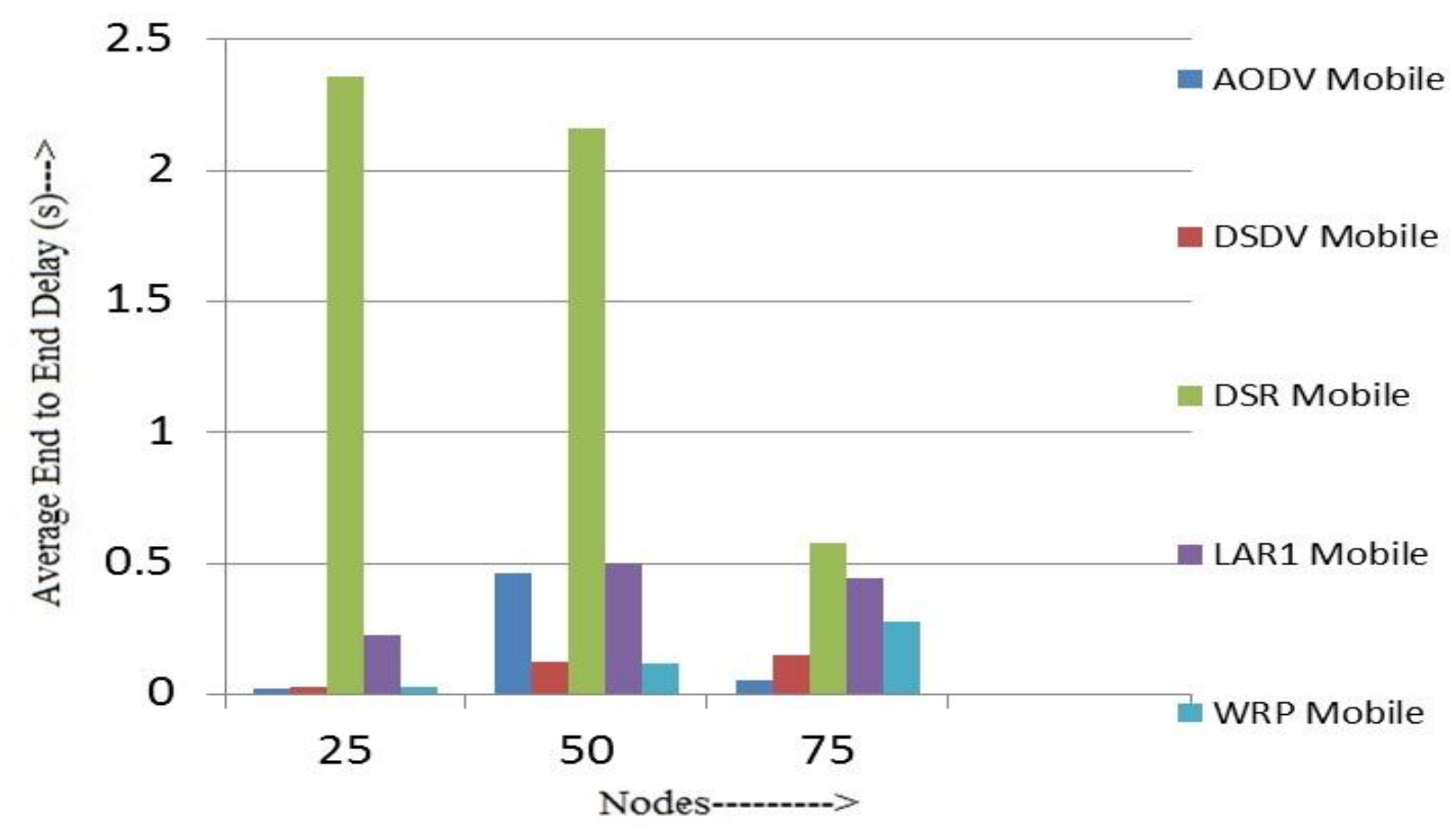

Fig 2: Average End to End Delay for 25, 50 and 75 Stationary nodes

\subsection{Throughput}

Figures 3 and 4 shows the variation in throughput of various routing protocols considered for mobile and stationary nodes with respect to node densities 25,50 and 75 nodes respectively. Table 4 and 5 shows values of throughput for different node densities for mobile and stationary nodes respectively. I find that throughput for DSR protocol is maximum and DSDV protocol is minimum for 25, 50 and 75 mobile node scenarios (Figure 3) and throughput for WRP protocol is maximum and again DSDV protocol is minimum for 25, 50 and 75 stationary node scenarios (Figure 4).
Table 4: Throughput for 25,50 and 75 mobile nodes

\begin{tabular}{|c|c|c|c|c|c|}
\hline $\begin{array}{c}\text { Node } \\
\text { with } \\
\text { mobility } \\
(10 \text { mps })\end{array}$ & AODV & DSDV & DSR & LAR1 & WRP \\
\hline 25 & 4550.8 & 4569.1 & 85687.8 & 4962.4 & 4597.2 \\
\hline 50 & 5223.8 & 4574.8 & 46271.2 & 5035.3 & 4645.8 \\
\hline 75 & 4584.3 & 4581.0 & 8189.2 & 5062.7 & 4847.3 \\
\hline
\end{tabular}




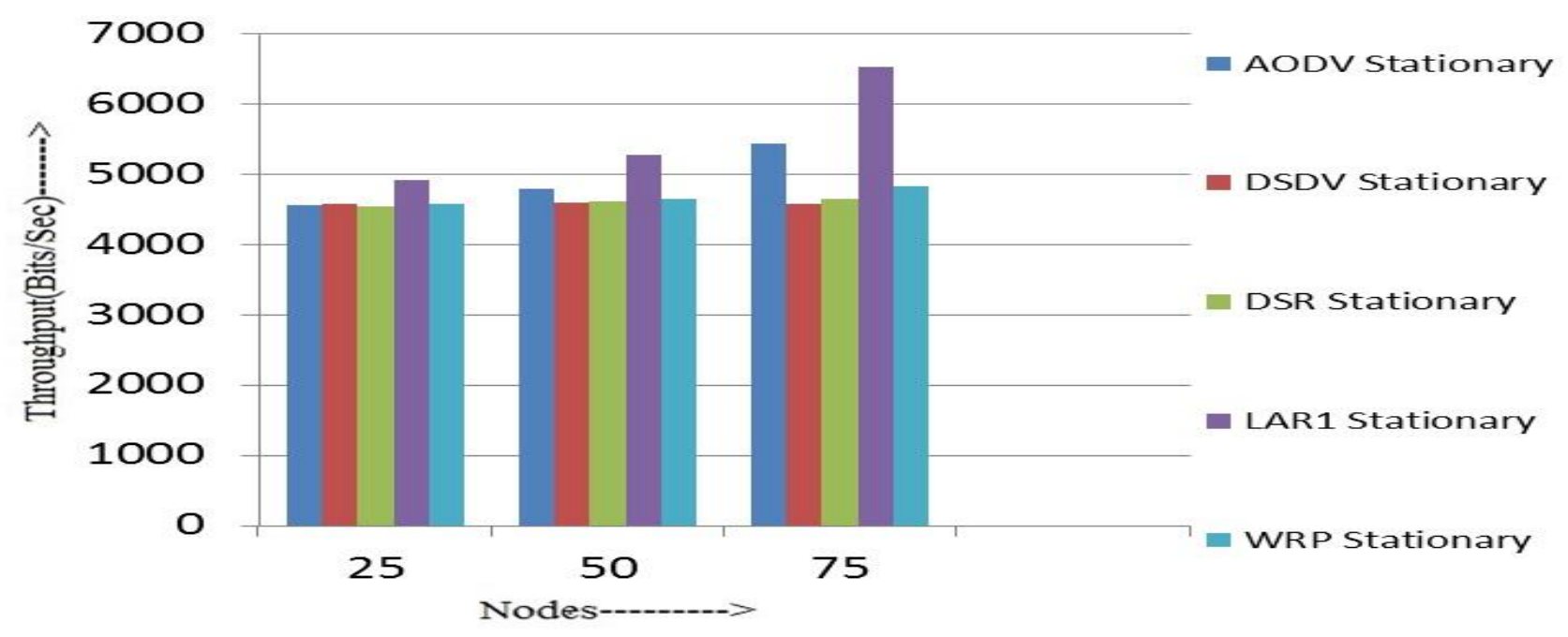

Fig 3: Throughput for 25, 50 and 75 Mobile nodes

Table 5: Throughput for 25, 50 and 75 Stationary nodes

\begin{tabular}{|c|c|c|c|c|c|}
\hline $\begin{array}{c}\text { Statio- } \\
\text { nary } \\
\text { node }\end{array}$ & AODV & DSDV & DSR & LAR1 & WRP \\
\hline 25 & 4558.6 & 4577.6 & 4551.0 & 4918.2 & 4583.8 \\
\hline 50 & 4792.7 & 4593.6 & 4609.2 & 5267.8 & 4647.4 \\
\hline 75 & 5439.8 & 4585.7 & 4643.7 & 6522.2 & 4822.9 \\
\hline
\end{tabular}

Fig 4: Throughput Delay for 25, 50 and 75 stationary nodes

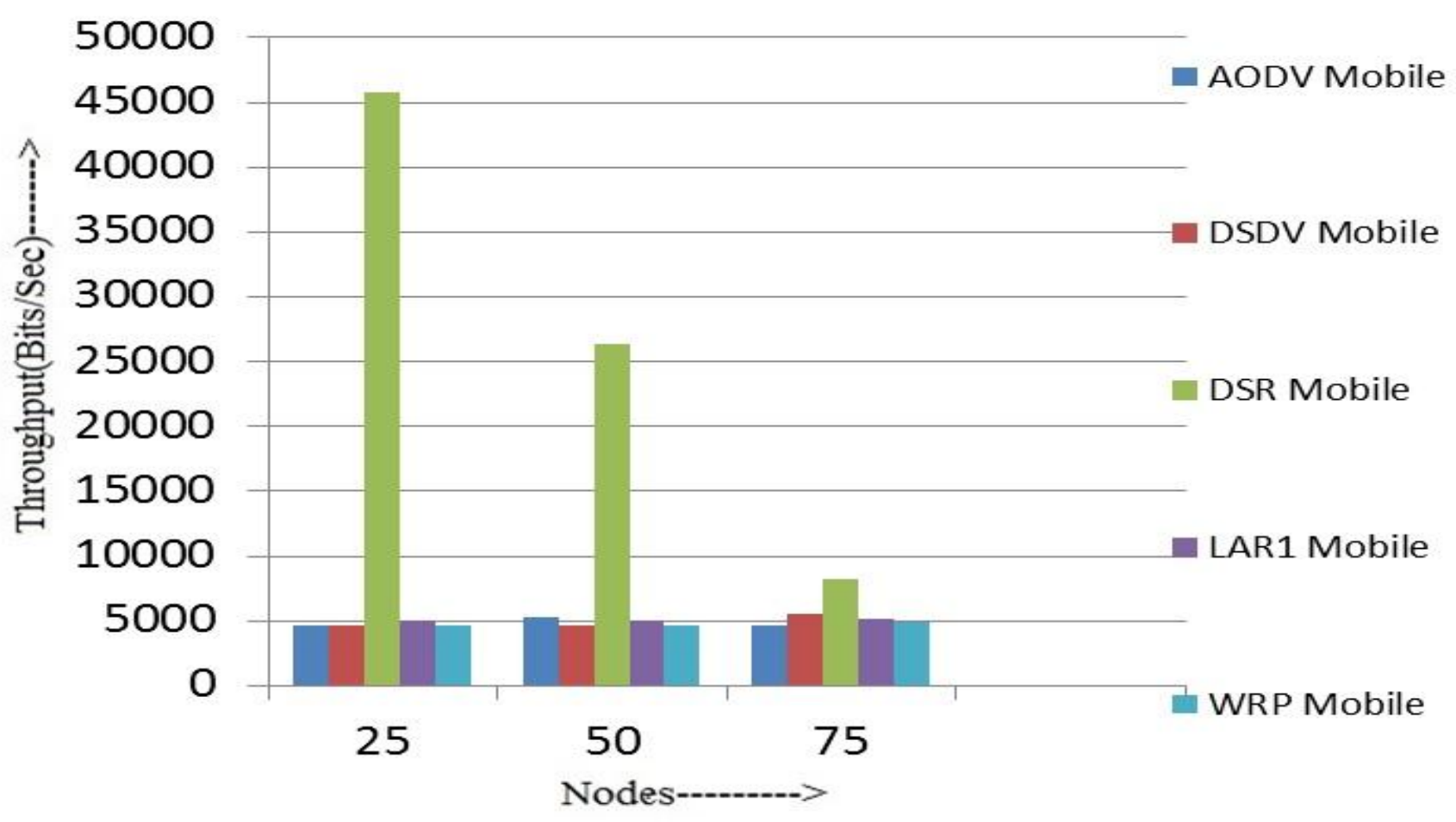




\subsection{Collisions}

Figures 5 and 6 shows the variation in collisions of various routing protocols considered for mobile and stationary nodes with respect to node densities 25,50 and 75 nodes respectively. Table 6 and 7 shows values of collisions for different node densities for mobile and stationary nodes respectively. I find that collisions for LAR1 protocol is maximum and WRP protocol is minimum for 25,50 and 75 mobile node scenarios (Figure 5) and collisions for LAR1 protocol is maximum and again WRP protocol is minimum for 25, 50 and 75 stationary node scenarios (Figure 6).
Table 6: Collisions for 25, 50 and 75 mobile nodes

\begin{tabular}{|c|c|c|c|c|c|}
\hline $\begin{array}{c}\text { Node } \\
\text { with } \\
\text { mobility } \\
(10 \mathrm{mps})\end{array}$ & AODV & DSDV & DSR & LAR1 & WRP \\
\hline 25 & 21.20 & 11.25 & 63.37 & 4122.5 & 11.03 \\
\hline 50 & 340.54 & 223.12 & 118.67 & 419.26 & 71.55 \\
\hline 75 & 93.64 & 1226.18 & 224.97 & 712.88 & 177.5 \\
\hline
\end{tabular}

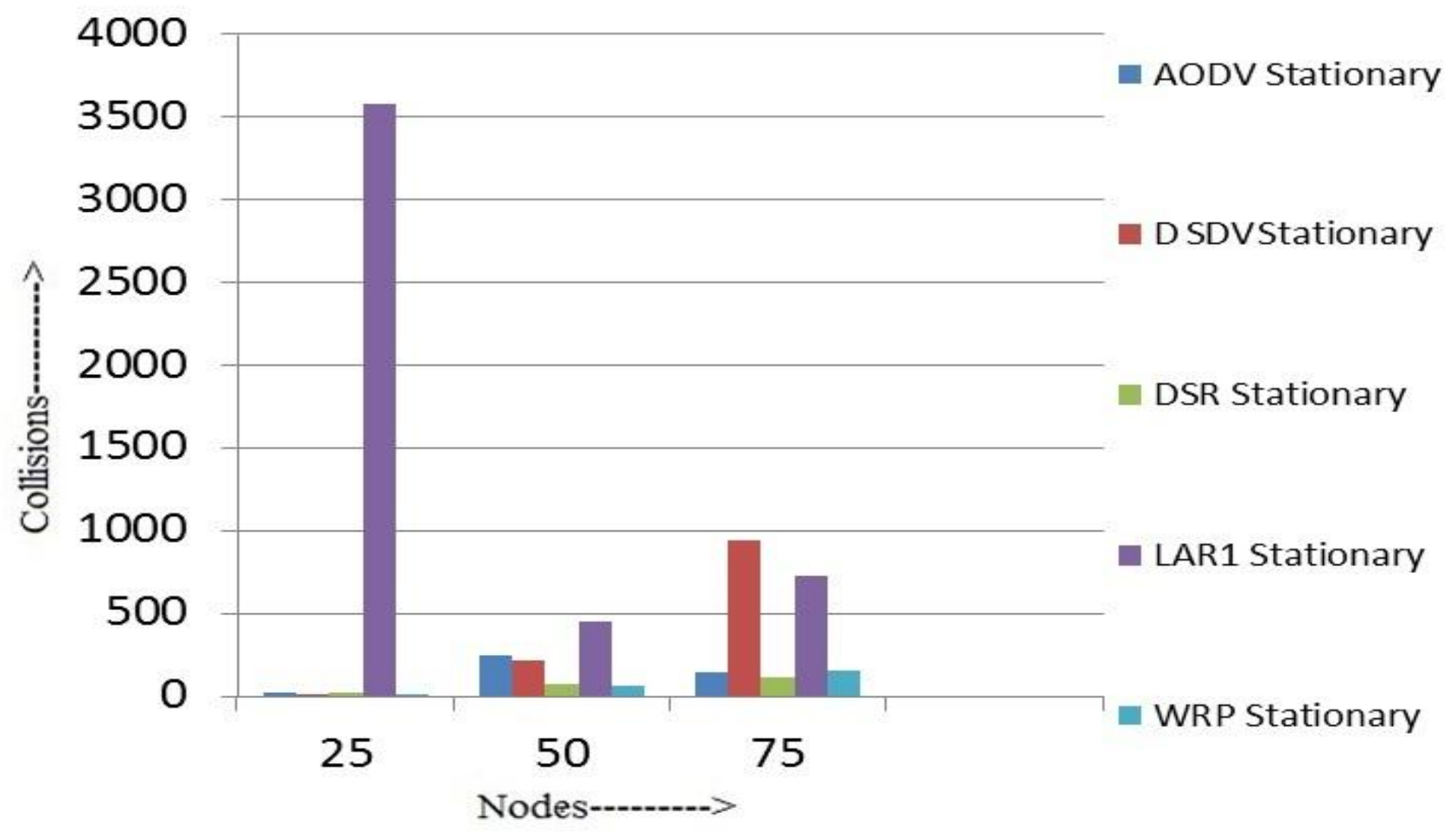

Fig 5: Collisions for 25, 50 and 75 Mobile nodes

Table 7: Collisions for 25, 50 and 75 Stationary nodes

\begin{tabular}{|c|c|c|c|c|c|}
\hline $\begin{array}{c}\text { Statio- } \\
\text { nary } \\
\text { node }\end{array}$ & AODV & DSDV & DSR & LAR1 & WRP \\
\hline 25 & 23.68 & 9.97 & 18.34 & 3580.21 & 10.24 \\
\hline 50 & 242.62 & 217.45 & 68.63 & 451.82 & 64.67 \\
\hline 75 & 145.64 & 941.21 & 110.66 & 728.84 & 156.78 \\
\hline
\end{tabular}




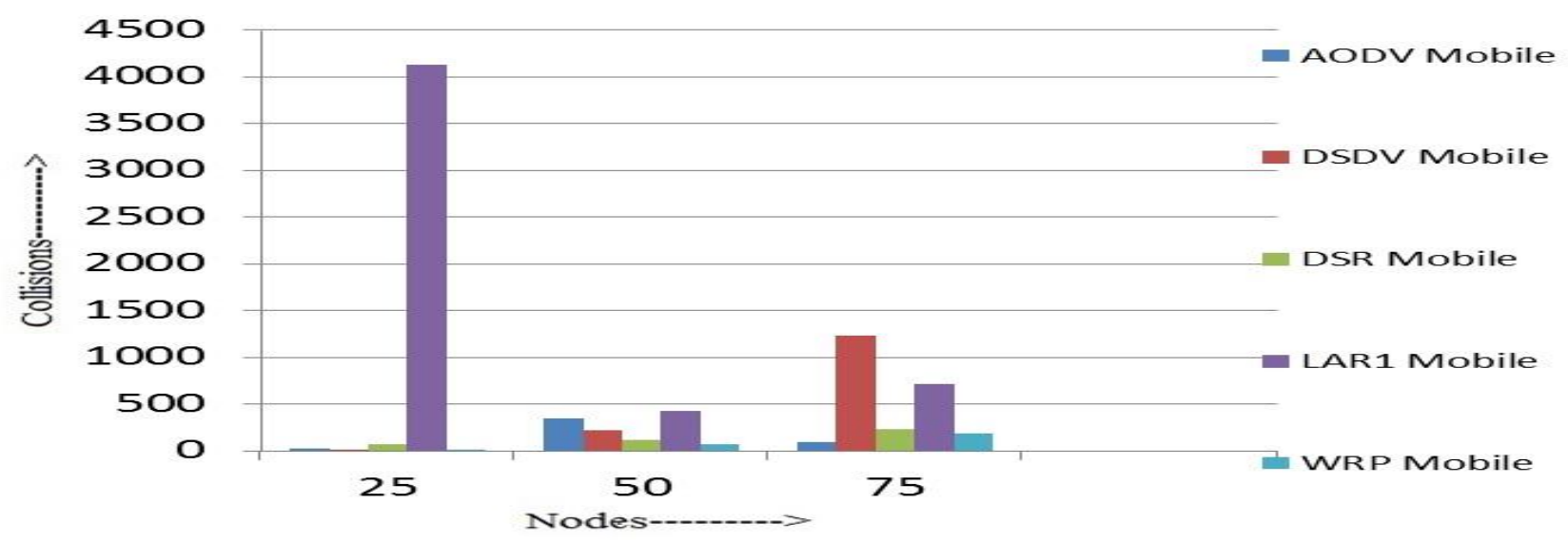

Fig 6: Collisions for 25, 50 and 75 Stationary nodes

\subsection{Energy Consumption}

Figures 7 and 8 shows the variation in energy consumption of various routing protocols considered for mobile and stationary nodes with respect to node densities 25, 50 and 75 nodes respectively. Table 8 and 9 shows values of energy consumption for different node densities for mobile and stationary nodes respectively. I find that consumption for WRP protocol is maximum and AODV protocol is minimum for 25, 50 and 75 mobile node scenarios (Figure 7) and energy consumption for WRP protocol is maximum and again DSR protocol is minimum for 25,50 and 75 stationary node scenarios (Figure 8).
Table 8: Energy Consumption for 25, 50 and 75 mobile nodes

\begin{tabular}{|c|c|c|c|c|c|}
\hline $\begin{array}{c}\text { Node } \\
\text { with } \\
\text { mobility } \\
(10 \mathrm{mps})\end{array}$ & AODV & DSDV & DSR & LAR1 & WRP \\
\hline 25 & 75.002 & 75.013 & 75.004 & 75.131 & 75.062 \\
\hline 50 & 75.010 & 75.023 & 75.006 & 75.013 & 75.104 \\
\hline 75 & 75.003 & 75.032 & 75.008 & 75.012 & 75.147 \\
\hline
\end{tabular}

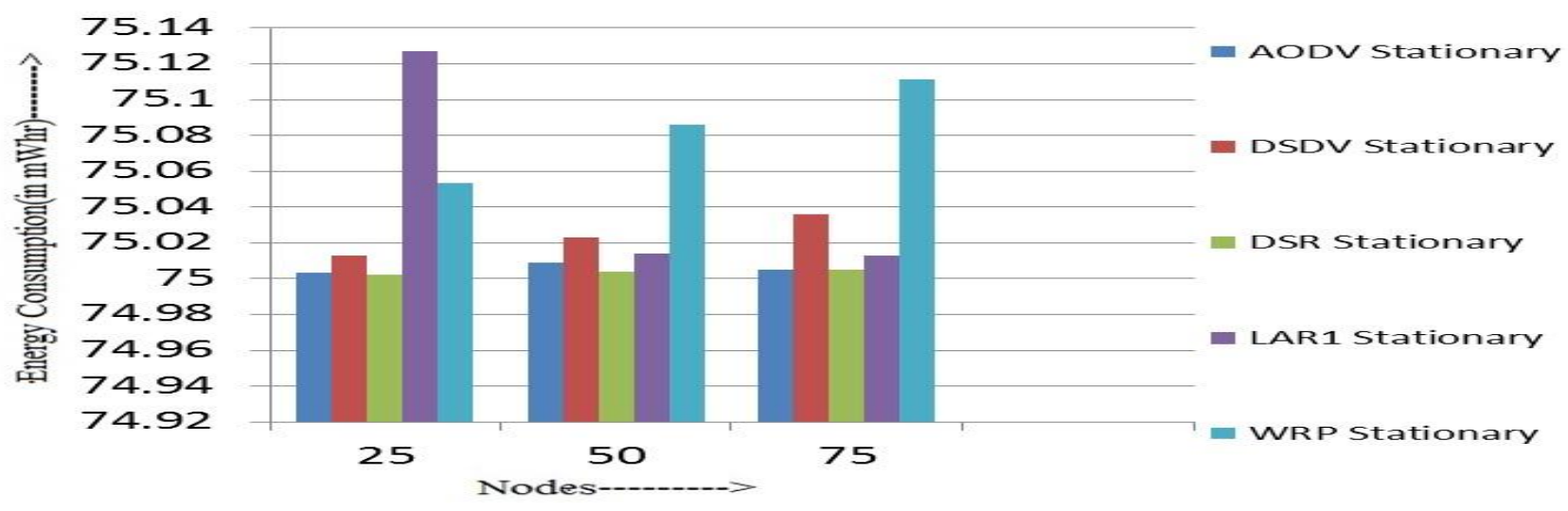

Fig 7: Energy Consumption for 25, 50 and 75 Mobile nodes

Table 9: Energy Consumption for 25, 50 and 75 Stationary nodes

\begin{tabular}{|c|c|c|c|c|c|}
\hline $\begin{array}{c}\text { Statio- } \\
\text { nary } \\
\text { node }\end{array}$ & AODV & DSDV & DSR & LAR1 & WRP \\
\hline 25 & 75.003 & 75.013 & 75.002 & 75.127 & 75.053 \\
\hline 50 & 75.009 & 75.023 & 75.004 & 75.014 & 75.086 \\
\hline 75 & 75.005 & 75.036 & 75.005 & 75.013 & 75.111 \\
\hline
\end{tabular}




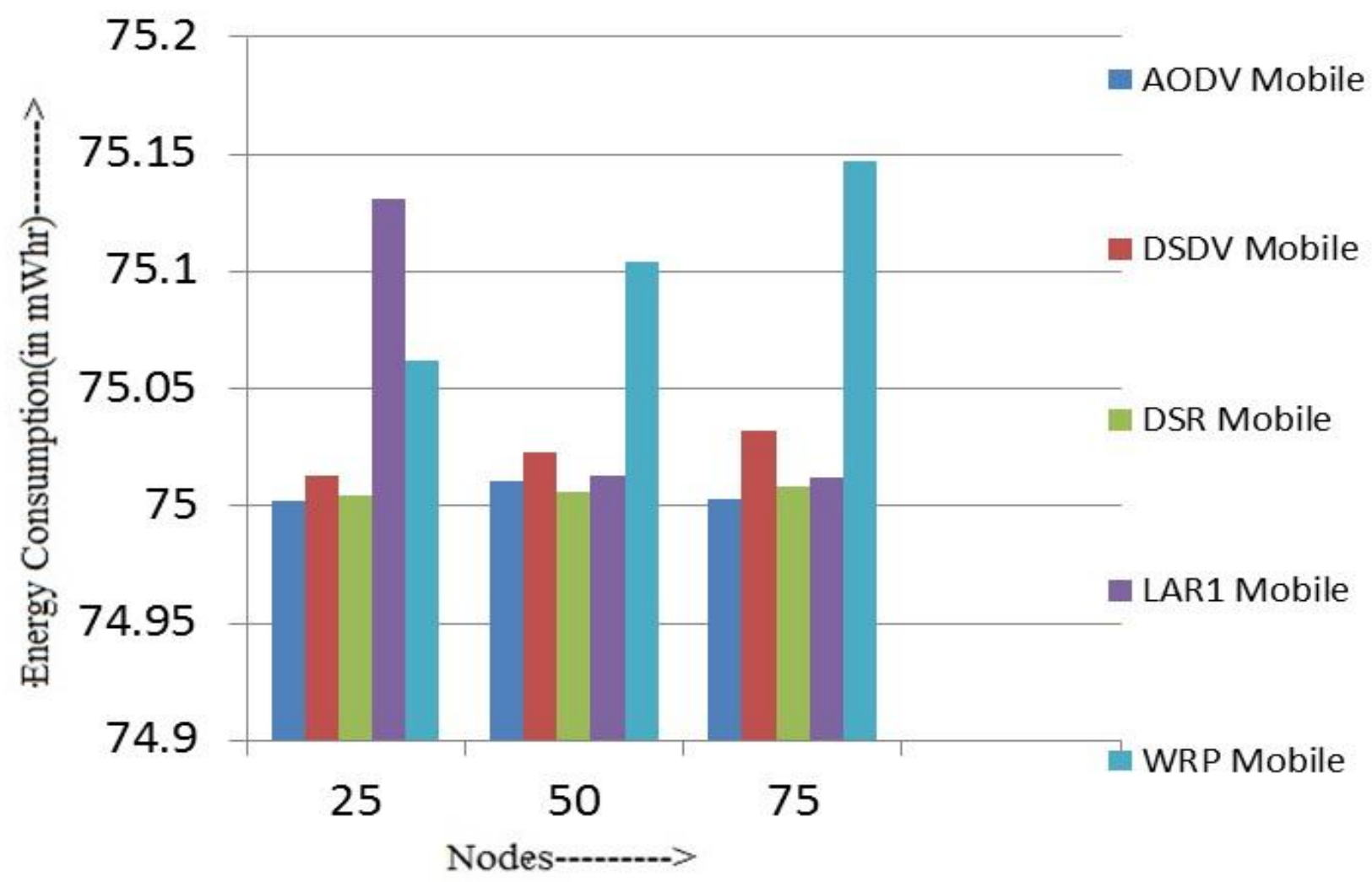

Fig 8: Energy Consumption for 25, 50 and 75 Stationary nodes

\section{CONCLUSION}

The performance evaluation of proactive (DSDV, WRP) and reactive (AODV, DSR, LAR1) routing protocols for stationary and mobile nodes are studied by varying the node density (25, 50 and 75) using GloMoSim 2.0.3 network simulator. From the results, these findings are observed.

Finding 1: In mobile node scenario, DSR protocol is having maximum average end to end delay and WRP is having minimum delay and in stationary nodes scenario, LAR1 performed maximum and DSR performed minimum.

Finding 2: In mobile node scenario, DSR protocol is having maximum throughput and DSDV is having minimum throughput and in stationary nodes scenario, WRP performed maximum and DSDV performed minimum.

Finding 3: In both mobile and stationary node scenarios, LAR1 protocol is having maximum collisions and WRP is having minimum collisions.

Finding 4: In mobile node scenario, WRP protocol is having maximum energy consumption and AODV is having minimum energy consumption and in stationary nodes scenario, WRP performed maximum and DSR performed minimum.

\section{REFERENCES}

[1] Singh Dinesh, Maurya Ashish K., Sarje Anil K.; "Comparative Performance Analysis of LANMAR,
LAR1, DYMO and ZRP Routing Protocols in MANET using Random Waypoint Mobility Model”, IEEE, pp. 6266, 2011.

[2] M Subramanya Bhat, D Shwetha, T Devaraju J.; "A Performance Study of Proactive, Reactive and Hybrid Routing Protocols using Qualnet Simulator," International Journal of Computer Application, vol. 28, no. 5, August 2011.

[3] Maan Fahimn, Mazhar Nauman; "MANET Routing Protocols vs Mobility Models: A Performance Evaluation", IEEE Conference ICUFN 2011, pp. 179185, 2011.

[4] Jain Rachit, khairnar Naresh B., Shrivastava Laxmi; "Comparative Study of Three Mobile Ad-hoc Network Routing Protocols under Different Traffic Source", IEEE International Conference on Communication Systems and Network Technologies 2011, pp. 104-107, 2011.

[5] Shurdi Olimpjon, Miho Rozeta, Kamo Bexhet, Kolici Vladi, Rakipi Alban; "Performance Analysis of Multicast Routing Protocols MAODV, ODMRP and ADMR for MANETs", IEEE International Conference on NetworkBased Information Systems 2011, pp. 596-601, 2011.

[6] Nayyar Anand; "Simulation Based Evaluation of Reactive Routing Protocols of MANET", IEEE Second International Conference on Advanced Computing \& Communication Technologies 2012, pp. 561-568, 2012.

[7] Khatkar Avni, Singh Yudhvir; "Performance Evaluation of Hybrid Routing Protocols in Mobile Adhoc Networks", IEEE Second International Conference on 
Advanced Computing \& Communication Technologies 2012, pp. 542-545, 2012.

[8] Vetrivelan N. and Reddy A.V., 2008. "Performance Analysis of Three routing Protocols for Varying MANET Size", Proceedings of the International Multi-Conference of Engineers and Computer Scientists.

[9] Uma M. and Padmavathi G., 2009. "A Comparative Study and Performance Evaluation of Reactive Quality of Service Routing Protocols in MANETs", Journal of Theoretical and Applied Information Technology, pp. 223-229

[10] Royer E. M. and Toh C. K., 1999. “A Review of Current Routing Protocols for Ad-Hoc Mobile Wireless Networks", IEEE Personal Communications Magazine, 46-55.

[11] Shaik Syed Basha, Setty S. P., 2010. "Performance Comparison of AODV, DSR and ANODR for Grid Placement Model" International Journal of Computer Applications (0975 8887), Volume 11, No.12, 6-9.

[12] Perkins C. E. and Royer E. M., 1999. "Ad Hoc Ondemand Distance Vector Routing," In Proceedings of the 2nd IEEE Workshop on Mobile Computing Systems and Applications, New Orleans, LA, 90-100.

[13] Johnson D., Maltz D. and Yih, 2003. "Dynamic Source Routing Protocol for Mobile AdHoc", http://www.ietf.org/internet-drafts/ draft ietf manet-DSR09.txt, IETF Internet draft.

[14] Raju Sree Ranga and Mungara Jitendranath. 2010. "Performance Evaluation of ZRP over AODV and DSR in Mobile Adhoc Networks Using Qualnet" European Journal of Scientific Research, Vol. 45, No.4. 658-674.
[15] Boukerche A., 2004. "Performance Evaluation of Routing Protocols for Ad Hoc Wireless Networks," Mobile Networks and Applications, Vol. 9, Kluwer Academic Publishers, 333-342.

[16] Mittal S., Kaur P.; "Performance Comparison of AODV, DSR and ZRP Routing Protocols in MANET'S," International Conference on Advances in Computing, Control \& Telecommunication Technologies, 2009 (ACT '09), pp.165-168, 28-29 Dec. 2009.

[17] Ismail, Z., Hassan, R.; "Performance of AODV routing protocol in Mobile Ad Hoc Network," International Symposium in Information Technology 2010 (ITSim), vol.1, pp.1-5, 15-17 June 2010.

[18] Rahman M. A., Anwar F., Naeem J., Abedin M. S. M. , "A simulation based performance comparison of routing protocol on Mobile Ad-hoc Network (proactive, reactive and hybrid)," International Conference on Computer and Communication Engineering 2010(ICCCE 2010), pp.1-5, 11-12 May 2010 .

[19] Maurya A. K., Singh D.; "Simulation based Performance Comparision of AODV, FSR and ZRP Routing Protocols in MANET," International Journal of Computer Application, vol. 12, no. 2, Novmber 2010.

[20] Malany A. B., Dhulipala V. R. S., Chandrasekaran R. M.; "Throughput and Delay Comparison of MANET Routing Protocols," Int. J. Open Problems Compt. Math., Vol. 2, No. 3, September 2009.

[21] Zayene M. A., Tabbane N.; "Performance evaluation of Location- Aided Routing protocols in ad hoc networks," Global Information Infrastructure Symposium, 2009 (GIIS '09), pp.1-6, 23-26 June 2009 